\title{
Structural concept of bitterness of peptides derived from food proteins using chemometric techniques
}

\author{
Anna Iwaniak, Monika Hrynkiewicz, Justyna Bucholska, Małgorzata Darewicz, Piotr Minkiewicz \\ Warmia \& Mazury University, Faculty of Food Science, Chair of Food Biochemistry, Pl. Cieszynski 1, Olsztyn, Poland
}

https://doi.org/10.17952/35EPS.2018.220

\section{Introduction}

Apart from the variety of biological functions, peptides derived from food proteins may affect the all five taste sensations i.e. bitter, salty, sour, sweet, and umami. Peptides with bitter taste are the most dominant as well as the most extensively studied comparing to the other tastes of these molecules. It is also reflected when searching the literature as well as biomolecule databases to find the information on peptides as tastants [1]. Bitter peptides are often produced by hydrolysis of proteins and the generated taste may be considered as an off-flavor and thus be found as the one of the limitations when producing biologically, chemically, and functionally active foods. It specially concerns the situation when a tastant peptide shows other bioactivities [1]. For example, many food protein-derived bitter peptides act also as ACE inhibitors i.e. cause blood pressure reduction. Although they are health-beneficial, their off-flavor taste may discourage the food technologists to use them as food additives [2].

Some data about the molecules of interest, including peptides, are available in the specific databases of biological and chemical information. It is the result of the popularity and continuous development of information technologies, which contributed to the increase of data repositories (databases) as well as programs helpful for biomolecules analyses. One of the scientific disciplines involving the statistics, mathematics, and formal logics to acquire the maximum information and knowledge about chemical systems is called a chemometrics. Chemometric techniques with combination of data provided in biological and chemical information are useful for multivariate analyses aiming to study the relationships between structure and function (activity) of molecules e.g. peptides. Thus, the aim of the study was to apply some multivariate chemometric techniques (see below) to find out which structural attributes (i.e. descriptors) may decide about the bitterness of peptides [3].

\section{Methods}

Sequences of bitter di- and tripeptides were acquired from the BIOPEP-UWM database of sensory peptides and amino acids [4]. The experimental measure of their bitterness (necessary for regression analyses) was Rcaf. i.e. bitterness relative to that of $1 \mathrm{mM}$ caffeine solution $\left(\mathrm{R}_{\text {caf. }}=1.0\right)$ [5]. These values were also found in the BIOPEP-UWM database. The variables (i.e. attributes, descriptors) were the numerical parameters describing the selected properties of each amino acid forming bitter di- and/ortripeptide sequence. They were: molecular weight, bulkiness, polarity, hydrophobicity, the number of carbon atoms, and the number of hydrogen atoms. First four descriptors were derived from ProtScale [6], while the other two from the Biological Magnetic Resonance Data Bank [7]. Finally well-conditioned matrices were obtained for 51 dipeptides and 12 variables and 51 tripeptides and 18 variables. These matrices were the foundation to perform PCA and MLR using Statistica13.1 ${ }^{\oplus}$.

\section{Results and Discussion}

The results of PCA and MLR calculations are shown in Table 1. The number of principal components (Comps.) in di- and tripeptide models was distinguished based on few criteria (data not shown). One of them was the percentage of cumulative variance explained, which usually should be at least $70 \%$ and in some cases $80 \%$. Based on the above-mentioned criterion, 4 and 5 Comps. were found statistically significant for di- and tripeptide datasets, respectively (see Table 1). They explained over $87 \%$ and $82 \%$ of cumulative variance, respectively. It was discovered that one of the attributes affecting the bitterness of both peptide datasets was molecular weight. Positive correlations were found for the residue located at the C-terminus of a di- and tripeptide chain, which was revealed in Comp. 1 (dipeptides) and Comp. 2 (tripeptides). This attribute was also characteristic for Comp. 2 (tripeptides) but describing middle amino acid. Such observation can be also related to the increasing number of carbon and hydrogen atoms in a peptide chain. The impact of the relatively high molecular weight of a residue on the bitter taste of peptides was confirmed by other authors. For example, Kim and Li-Chan [5] reported that 
high molecular weight of amino acids forming the peptide sequence affected its bitterness and also influenced its hydrophobicity. When looking at both datasets analyzed, peptides comprised mostly of F, Y and/or P (data not shown). According to the literature F and/or Y were reported to be bitter [5]. MLR analysis revealed the impact of a presence of $\mathrm{N}$-terminal bulky residue as well as the number of carbon atoms of C-terminal amino acid in dipeptide chain. No statistically significant attributes were found for MLR tripeptide model. According to the literature, it was found that peptides bitter taste was depended on the presence of hydrophobic/bulky (Cterminus) and basic/hydrophilic (N-terminus)of a peptide sequence. Despite the fact that results of tripeptides MLR were not statistically significant, our results obtained for di- and tripeptides were in line with the idea, according to which, bitterness of di-/tripeptidewas related to the physicochemical property of a specific amino acid present in a whole peptide sequence [8]. The majority of di- and tripeptides of our datasets were composed of hydrophobic C-terminal amino acid with a bulky chain like, e.g., V, L, and/or I which was indicated by variables revealed both by PCA and MLR. The detailed discussion on structure-bitterness of peptides using proposed approach was discussed in papers [9] and [10].

To conclude, when comparing both chemometric techniques applied, PCA (quite old and well-known chemometric method) revealed more attributes explaining their impact on peptide bitter taste than MLR. However, our approach was consistent with the results of other authors studying the relationships between structure and bitterness of peptides. Moreover, our applied chemometric techniques are universal and suitable for analysis structure-function relationships for peptides representing other bioactivities.

Table 1. Summary of PCA and MLR results calculated for bitter di- and tripeptide datasets.

Table 1: Summary of PCA and MLR results calculated for bitter di-and tripeptide datasets.

\begin{tabular}{|c|c|c|c|}
\hline \multicolumn{4}{|c|}{ Principal Component Analysis } \\
\hline \multicolumn{4}{|c|}{ Dipeptides } \\
\hline $\begin{array}{l}\text { \% cumulative } \\
\text { variance } \\
\text { explained }\end{array}$ & $\begin{array}{l}\text { Number of } \\
\text { statistically } \\
\text { significant } \\
\text { components }\end{array}$ & $\begin{array}{c}\text { Statistically significant variables forming the } \\
\text { specific component (Comp.); values in } \\
\text { brackets represent positive/negative } \\
\text { correlation }\end{array}$ & $\begin{array}{l}\text { Location of amino } \\
\text { acid in a peptide } \\
\text { chain assigned to } \\
\text { the variable } \\
\text { present in a } \\
\text { component }\end{array}$ \\
\hline \multirow[t]{4}{*}{$\sim 87.2$} & \multirow[t]{4}{*}{4} & $\begin{array}{l}\text { Comp. 1: molecular weight( }(-) \text {, bulkiness }(-) \text {, } \\
\text { number of carbon }(-) \text { and hydrogen atoms (- } \\
) \text {, molecular weight }(+) \text {, bulkiness }(+) \text {, number } \\
\text { of carbon }(+) \text { and hydrogen atoms }(+)\end{array}$ & $\begin{array}{l}\text { \}N-terminal } \\
\text { YC-terminal }\end{array}$ \\
\hline & & Comp. 2: hydrophobicity $(+)$ & \}C-terminal \\
\hline & & Comp. 3: polarity (+), hydrophobicity (-) & \}N-terminal \\
\hline & & Comp. 4: polarity(-) & \}C-terminal \\
\hline \multicolumn{4}{|c|}{ Tripeptides } \\
\hline \multirow[t]{5}{*}{$\sim 82.5$} & \multirow[t]{5}{*}{5} & $\begin{array}{l}\text { Comp. 1: molecular weight }(+) \text {, bulkiness }(+) \text {, } \\
\text { number of carbon }(+) \text { and hydrogen atoms } \\
(+)\end{array}$ & \} middle \\
\hline & & $\begin{array}{l}\text { Comp. 2: molecular weight }(+) \text {, bulkiness }(+) \text {, } \\
\text { number of carbon }(+) \text { and hydrogen atoms } \\
(+)\end{array}$ & C-terminal \\
\hline & & $\begin{array}{l}\text { Comp. 3: molecular weight(-), bulkiness(-), } \\
\text { number of carbon (-) and hydrogen atoms (-) }\end{array}$ & \} $\mathrm{N}$-terminal \\
\hline & & Comp. 4: hydrophobicity $(+)$ & N-terminal \\
\hline & & Comp. 5: polarity $(+)$ & N-terminal \\
\hline \multicolumn{4}{|c|}{ Multilinear regression } \\
\hline \multicolumn{4}{|c|}{ Dipeptides } \\
\hline $\mathrm{R}^{2}$ & $\alpha$ & $\begin{array}{l}\text { Statistically significant variables affecting } \\
\text { the bitterness of peptides; values in brackets } \\
\text { represent positive/negative correlation }\end{array}$ & $\begin{array}{l}\text { Location of amino } \\
\text { acid in a peptide } \\
\text { chain assigned to } \\
\text { the variable }\end{array}$ \\
\hline$\sim 0.4$ & 0.05 & $\begin{array}{l}\text { bulkiness(-) } \\
\text { number of carbon atoms }(+)\end{array}$ & $\begin{array}{l}\text { \}N-terminal } \\
\text { CC-terminal }\end{array}$ \\
\hline \multicolumn{4}{|c|}{ Tripeptides } \\
\hline$\sim 0.7$ & 0.05 & - & - \\
\hline
\end{tabular}




\section{Conclusions}

Bitterness of di- and tripeptides derived from food proteins depended on the presence of bulky, branched side residue or a ring (e.g. L, I, V, Y, F) in their sequences. Hydrophobicity of amino acids present in peptide sequences was one of the important attributes affecting their bitterness. Our approach involving some chemometric techniques to analyse structure-function of peptides can be useful for studying peptides with other biological functions.

\section{References}

[1] Iwaniak A., Minkiewicz P., Darewicz M., Hrynkiewicz M. 2016. Food protein-originating peptides as tastants - physiological, technological, sensory, and bioinformatic approaches. Food Res. Int., 89, 27-38;

[2] Li-Chan E. C. Y., 2015. Bioactive peptides and protein hydrolysates: research and challenges for application as nutraceuticals and functional food ingredients. Curr. Op. Food Sci., 1, 28-37;

[3] Iwaniak A., Minkiewicz P., Darewicz M., Protasiewicz M., Mogut D., 2015. Chemometrics and cheminformatics in the analysis of biologically active peptides from food sources. J. Funct. Foods, 16, 334-351;

[4] Iwaniak A., Minkiewicz P., Darewicz M., Sieniawski K., Starowicz P., 2016. BIOPEP database of sensory peptides and amino acids. Food Res. Int., 85, 155-161;

[5] Kim H., Li-Chan E. C. Y., 2006. Application of Fourier Transform Raman spectroscopy for prediction of bitterness of peptides. Appl. Spectroscopy 60(11), 1297-1306;

[6] Gasteiger E., Hoogland C., Gattiker A., Duvaud S., Wilkins M. R., Appel R. D., Bairoch A., 2005. Protein Identification and Analysis Tools on the ExPASy Server. In: J. M. Walker (Ed.)

[7] Ulrich E. L., Akutsu H., Doreleijers J. F., Harano Y., Ioannidis Y. E., Lin J., Markley J. L., 2008. BioMagResBank. Nucl .Acids Res. 36, D402-D408;

[8] Nongonierma A. B., FitzGerald R. J., 2016 Learnings from quantitative structure-activity relationship (QSAR) studies with respect to food protein-derived bioactive peptides: A review. RSC Adv., 6, 75400-75413;

[9] Iwaniak A., Hrynkiewicz M., Bucholska J., Minkiewicz P., Darewicz M., 2018. Understanding the nature of bitter-taste di- and tripeptides derived from food proteins based on chemometric analysis. J. Food Biochem., 2018e:12500;

[10] Iwaniak A., Hrynkiewicz M., Bucholska J., Darewicz M., Minkiewicz P., 2018. Structural characteristics of food protein-originatingdi- and tripeptides using principal componentanalysis. Eur. Food Res. Technol., 244, 10, 1751-1758.

\section{Acknowledgements}

This work was financed by the Warmia and Mazury University in Olsztyn (project number: 17.610.014-300) 